\title{
Laboratory Investigation of the Effect of Crude Oil Spill on Engineering Properties of Concrete.
}

\author{
Alban Chidiebere Ogbonna, Emmanuel Egwu Okoro, Tanko Daraha \\ Department Of Civil Engineering, Waziri Umaru Federal Polytechnic Birnin Kebbi, C/O P.O.Box 938 Birnin \\ Kebbi G.P.O, Kebbi State, Nigeria.
}

\begin{abstract}
The deterioration of reinforced concrete infrastructures as a result of the effect of Crude Oil spill on concrete structures particularly in the Niger Delta region of Nigeria has remained a great challenge to the engineering profession and the general public at large. Concrete interacts with substances within its environment. These interactions often have significant effect on the engineering properties of concrete made from ordinary Portland cement. Concrete specimens were prepared at 1:2:4 mix ratio and subject to three different curing media of concentrated crude oil, stimulated water/crude oil mix and potable water. The concrete specimens were cured in the media with environmental temperature of 25+20C and they were crushed at immersion ages of 7, 14, 21 and 28 days. The result obtained showed that different concentration of crude oil led to significant changes in the compressive strength of concrete made from ordinary Portland cement. This research also revealed that the rate of strength development is significantly low in the concentrated crude oil and crude oil/water mix curing media. Corrosion rate and chemical attack on concrete are high in the concentrated crude oil medium than in the crude oil/water mix as the reduction in compressive strength are in the ratio of 20:12. It was also observed that the three curing media led to increase in the compressive strength of concrete as the curing age increases.
\end{abstract}

Key words: Compressive strength, Concrete specimens, Curing age, Concrete structures, Immersion ages, Deterioration.

\section{Introduction:}

The deterioration of reinforced concrete structures as a result of the effect of crude oil spill on concrete structures particularly within the Niger Delta region of Nigeria has remained a great challenge to the engineering profession. Major engineering research have shown that deterioration of reinforced concrete in the marine and offshore environment is more severe than in any other environment and this has led to more laboratory and field investigations on the causes, effects and remedies of concrete deterioration in similar environment Daka, E. R and Ekweozo Ike (2004): Environmental Protection Agency EPA (2006): Jonnesari H and Moshreaf A (2005).

They observed that deterioration of concrete occur as a result of such factors as the physical and chemical characteristic of the marine environment together with the construction and maintenance techniques employed in erecting such concrete structures. Methods employed in curing, environmental pollutions such as crude oil spill and other factors contribute heavily towards the deterioration of reinforced concrete structures Memon N.A, Sumadi S.R, Ramli M (2007).

Ejeh S.P and Uche O.A.U (2009) different ways of protecting concrete against the aggressive effect of crude oil spill. Ejeh S.P and Uche O.A.U (2009) on their work on effect of crude oil spill on the compressive strength of concrete materials suggest that concentrated crude oil has the highest deterioration effect in concrete materials when compared to the values of the controlled medium (potable water). They further suggested that mixing and curing water should be free of crude oil spill to ensure the durability and stability of cement-based structures, as the compressive strength of materials will be affected if otherwise.

Ejeh S.P and Uche O.A.U (2009) observed that for over four decades that Nigeria have continued to experience remarkable increases in operational activities in her oil and gas exploration, exploitation, refining and product marketing which is concentrated in the Niger Delta region and that the region has been mired by various degree of health and environmental problems together with infrastructural deterioration. Regular crude oil spillage on the surface and sub surface water resources, erosion and drainage problems of the built environs culminating to incessant failures of buildings, bridges roads and other onshore structures and infrastructures have become a regular news item. Ejeh S.P and Uche O.A.U (2009) also reported on the various control measures, programmes and policies articulated by the government for the reduction of environmental problems associated with the oil and gas industry. But the problem remains whether the measures suggested so far are been implemented, monitored and reviewed efficiently. 
Crude oil is a naturally occurring liquid that can be distilled or refined to make fuels, lubrication oils, engine oils, kerosene, asphalt and other valuable products. It is a hydrocarbon composed mainly of hydrogen and carbon along with minor impurities like sulphur, nitrogen and oxygen. Crude oil is a naturally unrefined petroleum product composed of hydrocarbon deposits; crude oil can be reined to produce usable products such as gasoline, diesel and various forms of petrochemicals.

Kline T.R. (2004) in his work on sulphur pit assessment and repair strategies suggest that sulphrous components are aggressive medium for cement base materials. According to his report, concrete deterioration in sulphur pit environment is characterized by the concrete cement paste matrix being chemically modified and no longer exhibiting properties consistent with structural requirements. Reinforced concrete structures exposed to sulphurous products normally undergoes chemical reactions that expand the concrete fraction. This expansion always proves fatal to long term concrete durability and other serviceability requirements as it causes increase in volume. This problem can only be reduced by using sulphur resistant cement instead of ordinary Portland cement in reinforced concrete structures.

Nigerian crude oil has low sulphur contents and is predominantly of the light category. Nigerian crude oil has been rated as both sweet and sour as a result of sulphur content percentages which is greater or equal to $10 \%$ Ejeh S.P and Uche O.A.U (2009).Though sulphur content is expected to be removed during refining, it requires extra processing. Records and statistics have shown that most of the oil spillage in the Niger Delta area of Nigeria is of crude type, thereby endangering the aquatic, human, agricultural environments and the cement based infrastructures/structures.

The urgent need to investigate the effect of crude oil spill on the engineering properties of cement based concrete infrastructures has become necessary and this is what this research work tends to achieve and suggest sustainable solutions/remedies.

\section{Cement and Mixing Water:}

\section{Materials And Methods:}

Ordinary Portland cement brand manufactured by Sokoto Cement limited was used in the experiment. Potable water obtained from the Kebbi State Water Board was used in mixing the concrete.

Aggregates:

The fine aggregates used was naturally occurring river sharp sand obtained from Zauro River in Kebbi State of Nigeria, while the coarse aggregate was made from C.G.C. Nigeria Limited query site located at Yauri in Kebbi State.

\section{CRUDE OIL MEDIA:}

The crude oil was obtained from Port Harcourt Refining Company (PHRC) located at Eleme near Port Harcourt city, Rivers State, Nigeria and the crude oil properties were rated using the American Petroleum Institute (API) gravity scale degree, widely used in expressing quality of crude oil and this is shown in Table 1. The curing media were prepared into three concentrations of $100 \%$ undiluted crude oil labeled (A), $25 \%: 75 \%$ (1:4) crude oil portable/ water mix labeled (B) and Potable water labeled (C). The crude oil/potable water mix is to represent oil spillage in marine and Niger Delta region of Nigeria. These curing solutions were labeled A, B, and $\mathrm{C}$ respectively.

\section{Concrete Compression Test:}

The concrete specimens were prepared at the mix ratio of $1: 2: 4$ by weight of cement, fine aggregates and coarse aggregates at water cement ratio of 0.47 . The test concrete cubes were $150 \mathrm{~mm} \times 150 \mathrm{~mm} \times 150 \mathrm{~mm}$ and were made as soon as practicable after mixing. The filling of the mould was in three layers of $5 \mathrm{~cm}$ each. The concrete specimens were compacted manually using $16 \mathrm{~mm}$ diameter metal rod at 40 strokes per layer. A total number of forty eight (48) cubes were prepared. The samples were cured in three different media of crude oil concentration (A), crude oil/water mix concentration (B) and potable water (C) at an environmental temperature of $25^{\circ} \mathrm{C} \pm 2^{\circ} \mathrm{C}$. The specimens were marked and the curing media were renewed every seven days and maintained at the same temperature. Four cubes from each of the three curing media were crushed at 3,7,14 and 28 days respectively and the average compressive strength were recorded.

The results of the compressive tests are shown in Table 6 and 7 and in figure 3 and 4.

\section{AGGREGATE CRUSHING VALUE (A.C.V.) TEST:}

The aggregate crushing value test was performed on the coarse aggregate to determine the resistance of the coarse aggregate to crushing under gradually applied compressive load. $6.5 \mathrm{KG}$ of aggregates passing through $12.5 \mathrm{~mm}$ sieve and retained on $10 \mathrm{~mm}$ sieve were used. The aggregates were in surface dry condition and were filled into the standard cylinder measured in three layers of equal dept. Each layer was top tamped 25 
times with the tamping rod and finally leveled off using the tamping rod and finally leveled off using the tamping rod as the straight edge. The weight of the sample contained in the cylinder was measured and taken as A. The same weight of the sample was taken for the second and third test.

The apparatus, with test sample and plumber in position were placed on the compression testing machine and was loaded uniformly upto a total load of 400un in 10 minutes time. The load was released. All the material were removed from the cylinder and sieved on a $2.36 \mathrm{~mm}$ sieve. The fraction passing the sieve was weighed and labeled as (B).

\section{Aggregate Impact Value (A.I.V) Test:}

The aggregate impact value test gives the relative measure of the resistance of an aggregate to sudden shock or impact Mouli M and Khehafi H (2007): Udoeyo F.F and Dashibil P.U (2002). The test samples used consists of aggregates passing through sieve $12.5 \mathrm{~mm}$ and retained on sieve $10 \mathrm{~mm}$. The aggregates were even dried for a period of four hours at a temperature of $100^{\circ} \mathrm{C}$ to $110^{\circ} \mathrm{C}$ and cooled. The aggregates were filled about one third full and tamped with 25 strokes by the tamping rod. The above procedure was repeated for the other two portions which served as the second and third layers respectively. The net weight of the aggregate in the measure was determined (A) and the same weight of aggregate was used for the duplicate test on the same material.

The whole sample was filled into a cylindrical steel cup firmly fixed on the base of the machine. A hammer weighing $14 \mathrm{~kg}(0.14 \mathrm{KN})$ was raised to a height of $380 \mathrm{~mm}$ above the upper surface of the aggregate in the cup and allowed to fall freely on the aggregates. The test sample was subjected to a total of 15 of such below each being delivered at an internal of 0.45 seconds. The crushed aggregates were removed from the cup and the whole of it were sieved on sieve $2.36 \mathrm{~mm}$. The fraction passing the sieve was weighed to an accuracy of $0.1 \mathrm{~g}$ and the weight $\mathrm{B}$ was noted. The fraction retained on the sieve $2.36 \mathrm{~mm}$ was also weighed (C). The total weight $(\mathrm{B}+\mathrm{C})$ was calculated and compared with the initial weight A to check the accuracy of the test procedure.

2.2.4

\section{SIEVE ANALYSIS:}

For the purpose of this research work sieve analysis were conducted for both fine and coarse aggregates. The results of the sieve analyses are shown in figure $1 \& 2$ in Table $4 \& 5$. The sieve analysis involved the passing of original sample through a stack of sieves, arranged in descending order of the opening of the sieve, with larger sieve on the top. The material retained on each sieve after shaking, represents the fraction of the aggregate coarser then the sieve in question and finer then the sieve above. The weight of sample retained on each sieve was expressed as a percentage of the total weight of the sample which was used to calculate the cumulative percentage retained on each successive sieve. The percentage passing was plotted against the sieve sizes to obtain the grading curve of both the coarse aggregate and the fine aggregate.

\section{COMPRESSIVE STRENGTH OF CONCRETE CUBES: \\ III. Results And Discussion:}

The compressive strength test results of the concrete specimens cured in the various media were shown in table 6 and 7. The results show that the curing media have significant effect in the compressive strength of the concrete cubes. The values of the potable water medium maintained a consistent increase in the compressive strength as the curing ages increased. The crude oil media (A and B) also show significant increases in compressive strength as the age of curing increase but at a slower rate. The different in the compressive strength test results may be attributed to chemical properties of the crude oil and the chemical reactions taking place in the crude oil solution but absent in the potable water solution.

The reductions in strength can be related to the nature of crude oil absorption and the sulphate attack on the concrete. The term sulphate attack denote an increase in the volume of cement paste in concrete or mortar due to the chemical action between the products of hydration of cement and solution containing sulphates. In the hardened concrete, calcium aluminate hydrate $(\mathrm{C}-\mathrm{A}-\mathrm{H})$ can react with sulphate salt from outside. The product of the reaction is calcium sulphur aluminate forming within the frame work of hydrated cement paste. Because of the increase in volume of the solid phase which can go upto 227 percent, a gradual disintegration of concrete takes place, M.S. Shetty (2013). From the properties of Nigerian crude oil shown in Table 1 the crude oil is slightly acidic and contains $0.3 \%$ by weight of sulphur while portable water is neutral. Ordinary Portland cement being highly alkaline is susceptible to attack by the concentrated crude oil medium and the crude oil/water mix medium. The absorption of crude oil into the microstructure of the matrix of concrete may have caused dilation of the gel and weakening of the cohesive forces in the paste and hence low strength development of the concrete cured in media A and B.

This process termed "wetting - weakening effect" is consistent with the results of Ejeh S.P and Uche O.A.U (2009). When the values of the potable water medium are compared to the values from medium A and B, 
they are always higher and the other media of curing deteriorates with time as curing age increases - as shown in figure 3-The graph of the compressive strength development of concrete cured in different media. With the potable water as the benchmark, the values at potable water medium are subtracted from the values of media A and B to see the effect of each medium on the compressive strength of concrete. It is evident that immersing in crude oil and crude oil/water mix is aggressive to concrete material as the resistance of the concrete reduces with time and subsequently the reduction in the compressive strength of the specimens. Table 7 and Figure 4 show the percentage reduction in the compressive strength using the portable water medium as base. This reveals that for medium A, the reduction in compressive strength increases from $09 \%$ at the 7 days to $20 \%$ at the 28 days of curing, where as the crude oil/water mix has reduction of $05 \%$ at the 7 days and $12 \%$ of the 28 days. It can therefore be said that the concentrated crude oil medium has the most severe effect on concrete at short, medium and longer period of curing ages. From figure 4 the graph of percentage reduction of compressive strength of in media A and B it can be seen that the trend of variations in aggressiveness of the media may be linked to the sulphur contact of crude oil and other chemical reactions which may cause attention of paste composition with monosulphate phase converting to ettringite and also loss of bond between the cement paste and aggregates thereby creating overall loss in compressive strength of concrete.

\subsection{Results of Hardness Tests (A.C.V and A.I.V) of the Coarse Aggregate:}

The results of the hardness tests [Aggregate Crushing Value (ACV) and the aggregate Impact Value (AIV)] were presented in Table 2 and 3 respectively. The Aggregate Crushing Value of the coarse aggregate was found to be $28.5 \%$ while the aggregate impact value was $30 \%$.

\subsection{Results of the Grading Tests:}

The fine aggregate (sharp sand) with the grading results shown in Table 4 and in Figure I fall within the grading zone 2 of BS 812 (1985). The coarse aggregate grading results are shown in Table 5 and in figure 2.

Table 1: Properties of Nigerian Crude Oil:

\begin{tabular}{clc}
\hline $\boldsymbol{S} / \boldsymbol{N}$ & \multicolumn{1}{c}{ Parameters } & Magnitude \\
\hline 1. & Gravity Degree API & $>35.00$ \\
2. & Specific Gravity $15^{\circ} \mathrm{C}$ & 0.812 \\
3. & Sulphur content, \% by weight & 0.30 \\
4. & Moisture content, \% by volume & 0.40 \\
5. & Wax content, \% by weight & 7.0 \\
6. & Carbon residue, \% by weight & 2.10 \\
7. & Melting point of wax ${ }^{0} \mathrm{C}$ & 57 \\
8. & Viscosity at $21^{0} \mathrm{C}$ & 6.81 \\
9. & Acidity, $\mathrm{mg} / \mathrm{KOH} / \mathrm{g}$ & 0.05 \\
\hline
\end{tabular}

Source: Ejeh S.P and Uche O.A.U (2009)

Table 2: Results of the Aggregate crushing value Test:

\begin{tabular}{|c|c|c|c|}
\hline No. of Test & Test 1 & Test 2 & \\
\hline Weight of samples (g) & 3250 & 3250 & A \\
\hline Weight of fines pressing sieve $2.36 \mathrm{~mm}$ after applying $400 \mathrm{KN}$ uniform load & 942.5 & 910 & $\mathrm{~B}$ \\
\hline Aggregate Crushing Value (ACV) $(\%)$ & 29 & 28 & $B \quad 100$ \\
\hline Average aggregate crushing value (ACV) $(\%)$ & 28.50 & & $\bar{A} \times \overline{1}$ \\
\hline
\end{tabular}

Table 3: Results of the Aggregate Impact value value Test

\begin{tabular}{|c|c|c|c|}
\hline No. of Test & Test 1 & Test 2 & \\
\hline Weight of samples (g) & 930 & 930 & A \\
\hline $\begin{array}{l}\text { Weight of fines pressing sieve } 2.36 \mathrm{~mm} \text { after applying } 400 \mathrm{KN} \text { uniform } \\
\text { load }\end{array}$ & 288.3 & 269.7 & B \\
\hline Aggregate Crushing Value (ACV) (\%) & 31 & 29 & $B \times 100$ \\
\hline Average aggregate crushing value (ACV) (\%) & 30 & & \\
\hline
\end{tabular}

Table 4: Result of grading test for fine aggregate:

\begin{tabular}{|c|c|c|c|c|c|c|}
\hline $\begin{array}{l}\text { Sieve Size } \\
(\mathrm{mm})\end{array}$ & $\begin{array}{c}\text { Weight } \\
\text { retained }(g)\end{array}$ & $\begin{array}{c}\text { Cumulative } \\
\text { Weight Retained } \\
\text { (g) } \\
\end{array}$ & $\begin{array}{c}\text { Percentage } \\
\text { Retained (\%) }\end{array}$ & $\begin{array}{c}\text { Cumulative } \\
\text { Percentage } \\
\text { Retained } \\
\end{array}$ & $\begin{array}{c}\text { Weighty } \\
\text { Passing (g) }\end{array}$ & $\begin{array}{l}\text { Percentage } \\
\text { passing }(\%)\end{array}$ \\
\hline 10 & 0 & 0 & 0 & 0 & 500 & 100 \\
\hline 4.75 & 26.75 & 26.75 & 4.35 & 4.35 & 478.25 & 95.65 \\
\hline 2.36 & 68.50 & 95.25 & 8.70 & 13.05 & 434.75 & 95.65 \\
\hline 1.18 & 53.50 & 148.75 & 20.70 & 33.75 & 331.25 & 66.25 \\
\hline 0.60 & 140.55 & 289.30 & 29.11 & 62.86 & 185.7 & 37.14 \\
\hline 0.30 & 134.40 & 423.70 & 26.88 & 89.74 & 51.3 & 10.26 \\
\hline
\end{tabular}


Laboratory Investigation Of The Effect Of Crude Oil Spill On Engineering Properties Of Concrete.

\begin{tabular}{|c|c|c|c|c|c|c|}
\hline 0.15 & 46.15 & 469.85 & 9.23 & 98.97 & 5.15 & 1.03 \\
\hline 0.075 & 15.55 & 485.4 & 0.11 & 99.08 & 4.6 & 0.92 \\
\hline Passing 0.075 & 14.6 & 500 & 0.92 & 100.00 & 0.00 & \\
\hline Total & 500 & & 100 & & & \\
\hline $\begin{array}{l}\text { Sieve Size } \\
(\mathrm{mm})\end{array}$ & $\begin{array}{c}\text { Weight } \\
\text { retained }(\mathrm{g})\end{array}$ & $\begin{array}{c}\text { Cumulative } \\
\text { Weight Retained } \\
\text { (g) }\end{array}$ & $\begin{array}{c}\text { Percentage } \\
\text { Retained (\%) }\end{array}$ & $\begin{array}{c}\text { Cumulative } \\
\text { Percentage } \\
\text { Retained }\end{array}$ & $\begin{array}{c}\text { Weighty } \\
\text { Passing (g) }\end{array}$ & $\begin{array}{l}\text { Percentage } \\
\text { passing }(\%)\end{array}$ \\
\hline 40 & 0 & 0 & 0 & 0 & 1300 & 100 \\
\hline 20 & 305.24 & 305.24 & 23.48 & 23.48 & 994.76 & 76.52 \\
\hline 12.5 & 542.49 & 847.73 & 41.73 & 65.21 & 452.27 & 34.79 \\
\hline 10 & 323.18 & 1170.91 & 24.86 & 90.07 & 129.09 & 9.93 \\
\hline 4.75 & 125.06 & 1295.97 & 9.62 & 99.69 & 4.03 & 0.31 \\
\hline 2.36 & 4.03 & 1300 & 0.31 & 100 & & \\
\hline Total & 1300 & & & & & \\
\hline
\end{tabular}

Table 6: Comparison of the average compressive strength for different caring media:

\begin{tabular}{|c|c|c|c|c|}
\hline \multirow[t]{2}{*}{$\mathbf{S} / \mathbf{N}$} & \multirow{2}{*}{$\begin{array}{l}\text { Age in } \\
\text { Days }\end{array}$} & Water Medium (C) & $\begin{array}{l}\text { Concentrated Crude Oil Medium } \\
\text { (A) }\end{array}$ & Crude Oil/ mix Medium (B) \\
\hline & & $\begin{array}{l}\text { Average Comprehensive } \\
\text { Strength }\left(\mathrm{N} / \mathrm{mm}^{2}\right)\end{array}$ & $\begin{array}{l}\text { Average Compressive Strength } \\
\left(\mathrm{N} / \mathrm{mm}^{2}\right)\end{array}$ & $\begin{array}{c}\text { Average Compressive Strength } \\
\left(\mathrm{N} / \mathrm{mm}^{2}\right)\end{array}$ \\
\hline 1. & 7 & 26.42 & 24.17 & 25.06 \\
\hline 2. & 14 & 31.28 & 27.08 & 29.37 \\
\hline 3. & 21 & 35.22 & 29.19 & 32.23 \\
\hline 4. & 28 & 41.02 & 32.66 & 36.11 \\
\hline
\end{tabular}

Table 7: Percentage reduction in the average compressive strength for different curing media:

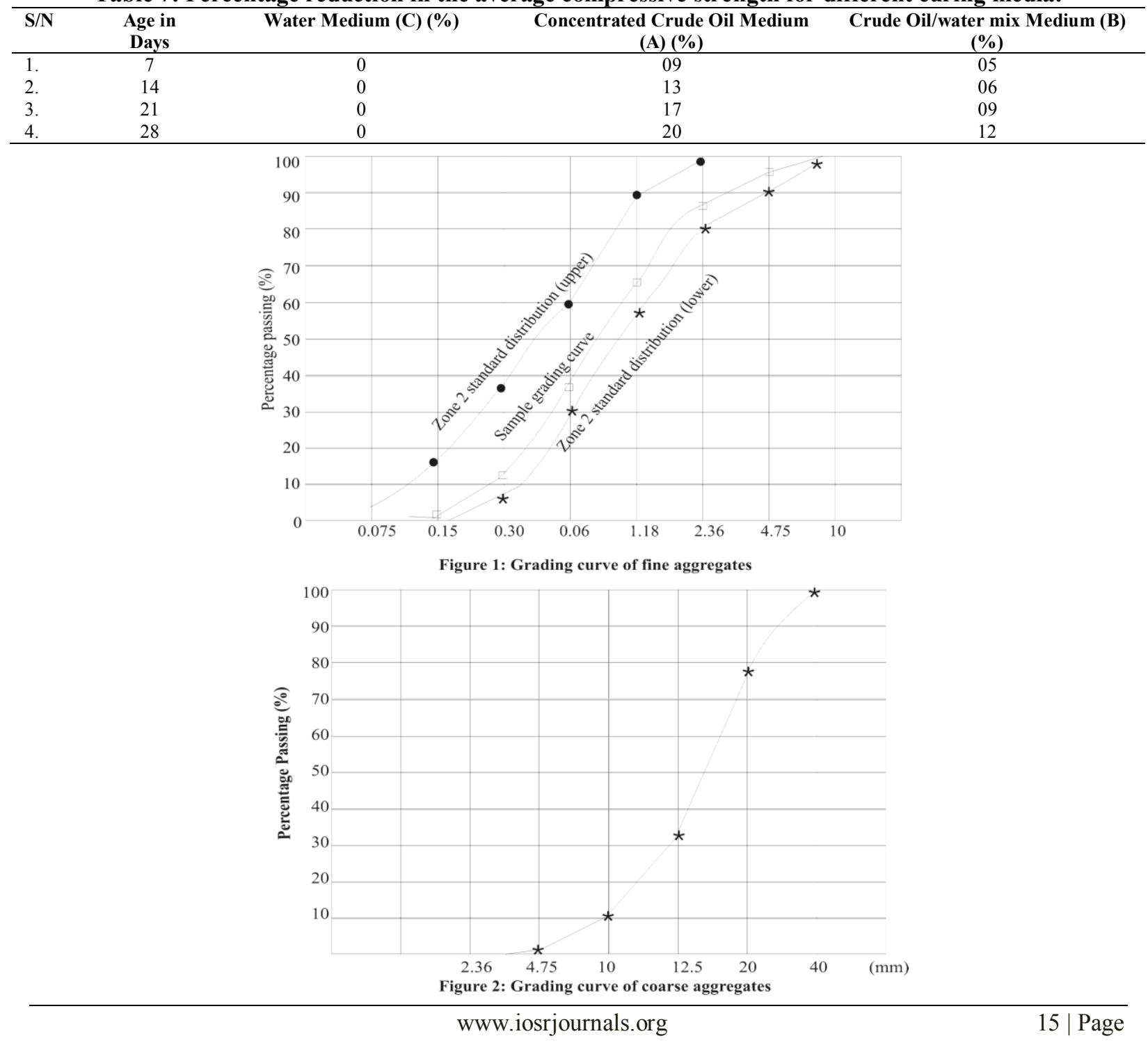




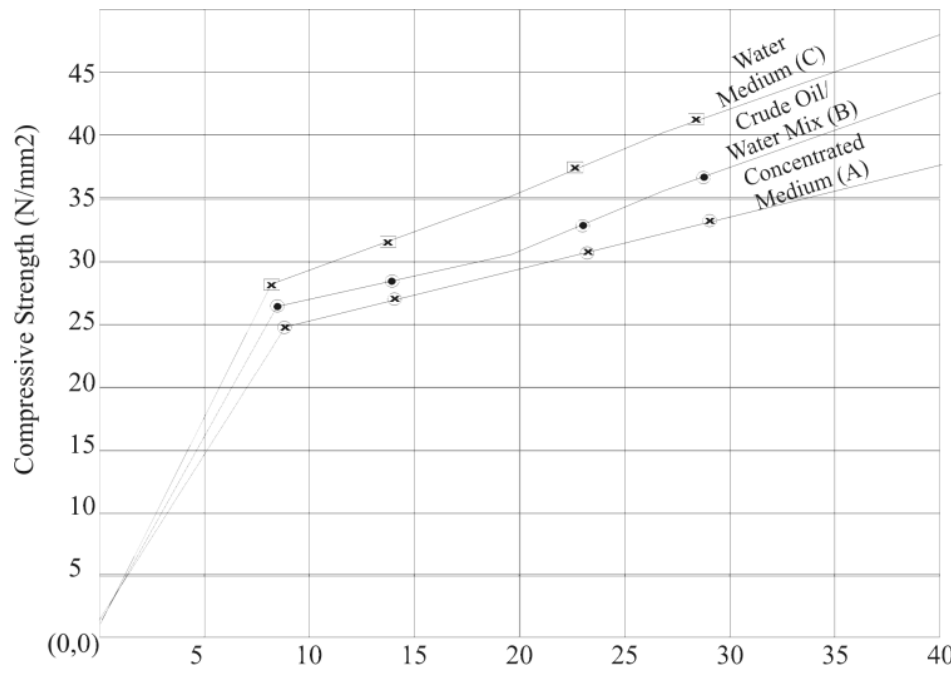

Figure 3: Rate of Development of Compressive Strength of Concrete Specimens cured in Different Media

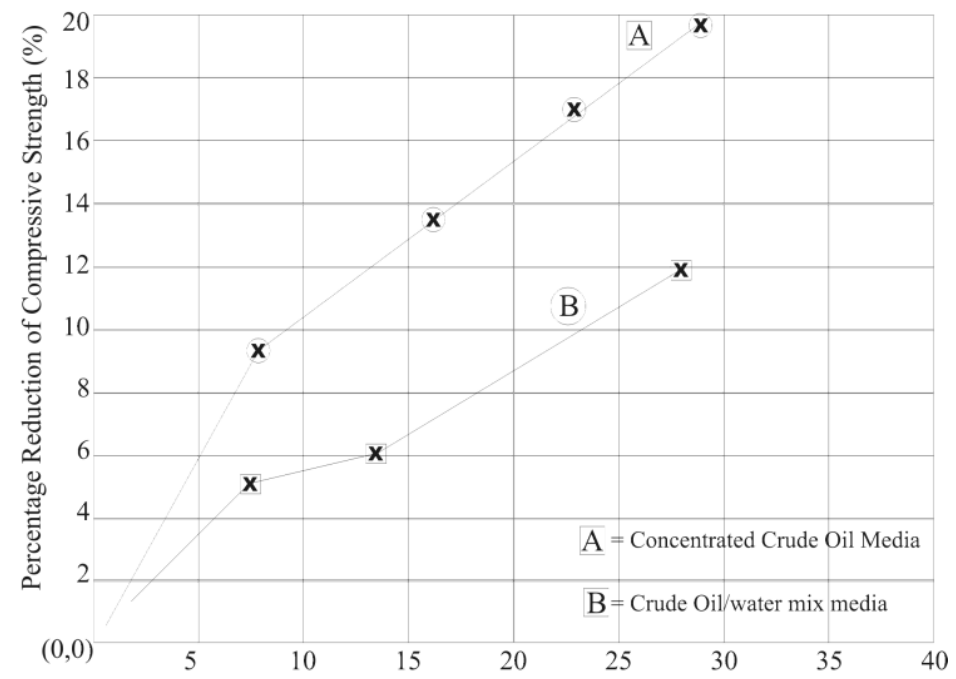

Figure 4: Percentage Reduction in the average compressive strength of concrete specimen in different curing media (A \& B)

\section{Conclusion:}

The Based on the results discussed above. The outcome of the investigation revealed that:

(1) Concentrated crude oil medium and the crude oil/water mix medium contain one form of compound or the other consider injurious to cement-based material.

2. The costal and offshore structures are directly or indirectly exposed to simultaneous action of a number of physical and chemical deterioration processes due to crude oil spillage.

3. The concrete structures exposed to severe crude oil are subjected to attack and that crude oil solutions find entry into porous concrete and react with the hydrated cement products, which leads to the increase in volume of cement paste in concrete and gradual disintegration of concrete.

4. The rate of crude oil attack on concrete increases with increase in concentration of crude oil.

5. All concrete specimens cured in potable water medium show increased in compressive strength at a steady rate at the curing ages increases.

6. The ordinary Portland cement has weak resistance to crude oil attack as they displayed slow compressive strength development and great reduction in strength in all ages of exposure in concentrated crude oil and crude oil/water mix media when compared to the potable water medium.

7. To ensure durability and stability of cement-bared concrete structures, mixing and curing water should be free of crude oil spill as the engineering properties of the concrete will be adversely affected if otherwise. 


\section{References:}

[1]. Daka, E.R and Ekweozo Ike, 2004. Effect of size on the Acute Toxity of Crude Oil to the mangrove oyster, caresostreagasar. Journal of applied science and environmental management, (8)2:19-22.

[2]. Environmental Protection Agency (EPA), 2006. The Behaviour and Effects of oil spill on aquatic environment, EPA Office of Emergency and remedial response, USA.

[3]. Ejeh S.P and Uche O.A, U, 2009. Effect of crude oil spill of compressive Strength of concrete materials. Journal of applied science research 5 (10): 1756- 1761

[4]. Jonnesari H. and Moshreaf A. 2005. The Bond between Repair materials and concrete substrate in marine environment, Asian Journal of Civil Engineering (Building and Housing) 6 (4): 267-272.

[5]. Kline, T.R., 2004. Sulfur Pit Assessment and Repair Strategies, Structural Preservation Systems inc, Houston, Texas, USA.

[6]. Memon, N.A., Sumadi S.R., Ramli, M. 2007. Performance of high workability Slag-cement mortar for ferrocement. Building and Environment; 2710- 2717.

[7]. Mouli, M., Khelafi, H. 2007. Properties of lightweight concrete made with Crushed natural pozzolana as coarse aggregate. Technology and Economic Development of Economy. Vol. XIII, No 4 Pp. 259-265.

[8]. Neville, A. M. (2000). Properties of Concrete. Pitman, New York, United States.

[9]. Udoeyo, F. F. and Dashibil, P. U. (2002). "Sawdust ash as concrete Material.” Journal of Materials in Civil Engineering, 14(2), 173176. 